\title{
CERTAIN ITERATIVE METHODS FOR THE NONLINEAR LEAST SQUARES PROBLEM
}

This paper is concerned with the problem of solving nonlinear operator equation in the sense of least squares.

Let $F(x)$ be a differentiable (sufficiently often with respect to $x$ ) operator of one Hilbert space, $H_{1}$, another, $H_{2}$, and such that inverse $\left[F^{\prime}(x)\right]^{-1}$ may fail to exist.

To solve the equation

$$
\left[F^{\prime}(x)\right]^{*} F(x)=0
$$

we consider the iterative methods of type

$$
x_{k+1}=x_{k}-Q\left(x_{k}, A_{k}\right) \quad(k=0,1, \ldots),
$$

where $Q\left(x, A_{k}\right)$ - is an operator of $H_{1}$ into itself and $A_{k}$ - is an approximation to the pseudoinverse $\left[F^{\prime}\left(x_{k}\right)\right]^{+}$with

$$
A_{k}=A_{k} P_{k}, \quad\left\|\left(P_{k}-F^{\prime}\left(x_{k}\right) A_{k}\right) F\left(x_{k}\right)\right\| \leqslant \gamma_{k}\left\|P_{k} F\left(x_{k}\right)\right\| \quad\left(\gamma_{k}<1\right) .
$$

Without proof we shall state a basic convergence theorem concerning the methods of type (2) examined in $\left[{ }^{1-2}\right]$. We shall construct two rapidly convergent iterative methods like those of ${ }^{\left[{ }^{1-5}\right]}$ not requiring linear operators to be inverted and consider also some acceleration possibilities discussed in $\left[^{6}\right]$ (see methods $4^{\circ}$ and $6^{\circ}$ in section 3 ). Making use of the basic theorem we shall prove their convergence to a solution of the equation (1), establish their convergence rates and illustrate the methods by some numerical examples.

1. B a sic theorem. For a closed subspace $S$ of a Hilbert space $H$, we let by $P_{\mathrm{S}}$ denote the orthogonal projector of $H$ onto $S$. Throughout this paper we shall assume that the range $R\left(F^{\prime}(x)\right)$ is closed; for simplicity we shall use the following notations $R(x)=R\left(F^{\prime}(x)\right), R^{*}(x)=$ $=R\left(\left[F^{\prime}(x)\right]^{*}\right), P_{k}=P_{R\left(F^{\prime}\left(x_{k}\right)\right)}$ and $P_{k}^{*}=P_{R\left(\left[F^{\prime}\left(x_{k}\right)\right]^{*}\right)}$.

Assume that $\left\{x_{k}\right\}$ generated by (2) satisfy the condition

$$
\left\|P_{k+1} F\left(x_{k+1}\right)\right\| \leqslant \sum_{v=1}^{n_{1}} \omega v \gamma^{a_{v}}\left\|P_{k} F\left(x_{k}\right)\right\|^{b_{v}}+\sum_{i=p}^{n_{2}} c_{i}\left\|P_{k} F\left(x_{k}\right)\right\|^{i} \quad\left(a_{v}, b_{v} \geqslant 0\right),
$$

and the quantities $\gamma_{k}$ can be expressed in the form of

$$
\gamma_{k+1}=\left(\gamma_{k}+h\left\|P_{k} F\left(x_{k}\right)\right\|\right)^{q}, \quad \gamma_{0}+h\left\|P_{0} F\left(x_{0}\right)\right\|<1,
$$

or vanish in the limit as $k \rightarrow \infty$ according to another rule, or $\gamma_{k} \leqslant \gamma<1$ 
$(k=0,1, \ldots)$ while $\gamma$ can as well amount to zero. There $\omega_{v}, c_{i}, h$ are certain nonnegative constants with the exception of $c_{p}>0$.

If the quantities $\gamma_{k}$ are defined by (B), we shall introduce sequences $\left\{b_{k}\right\}$ and $\left\{d_{k}\right\}$. Let be $s=\min _{v} b_{v}$ and $l=\min _{v=s} a_{v}$ for all terms in $(\mathrm{A})$ with $\omega_{v} \neq 0$. We define for $a_{v}+b_{v} \geqslant p$ with $\omega_{v} \neq 0$ and $q \geqslant p$

$$
\begin{gathered}
b_{k} \geqslant \max \left\{\gamma_{k},\left\|P_{k} F\left(x_{k}\right)\right\|\right\}, \\
d_{k}=\max \left\{\sum_{v=1}^{n_{1}} \omega_{v} b_{k}^{a_{v}+b_{v}-p}+\sum_{i=p}^{n_{2}} c_{i} b_{k}^{i-p},(1+h)^{q} b_{k}^{q-p}\right\},
\end{gathered}
$$

and for $l<p-s$ and $q \geqslant \frac{p(p-s)}{l}$

$$
\begin{gathered}
b_{k} \geqslant \max \left\{\gamma_{k}^{\frac{l}{p-s}},\left\|P_{k} F\left(x_{k}\right)\right\|\right\}, \\
d_{k}=\max \left\{\sum_{v=1}^{n_{1}} \omega_{v} \frac{(p-s) a_{k}+l\left(b_{v}-p\right)}{l}+\sum_{i=p}^{n_{2}} c_{i} b_{k}^{i-p},(1+h)^{\frac{q l}{p-s}} b_{k}^{\frac{q l}{p-s}-p}\right\} .
\end{gathered}
$$

On the occasion of $\gamma_{k}=0$, we denote by

$$
d_{k}=c_{p}+\sum_{i=p+1}^{n_{2}} c_{i}\left\|P_{k} F\left(x_{k}\right)\right\| i-p=c_{p}+\sum_{i=p+1}^{n_{2}} c_{i} b_{k}^{i-p} .
$$

If only any coefficient $\omega_{v} \neq 0$, then in the case of $\gamma_{0} \geqslant \gamma_{1} \geqslant \ldots \geqslant \gamma_{k} \geqslant \ldots$ $\geqslant 0$ we take

$$
\delta_{k}^{(1)}=\sum_{v=1}^{n_{1}} \omega_{v} \gamma_{k}^{a} v\left\|P_{k} F\left(x_{k}\right)\right\|^{b_{v}-1}+\sum_{i=p}^{n_{2}} c_{i}\left\|P_{k} F\left(x_{k}\right)\right\|^{i-1} .
$$

If there is at least a coefficient $\omega_{v} \neq 0$ with $b_{v} \geqslant 1$ and $\gamma_{k} \leqslant \gamma<1$, then $\gamma$ stands for $\gamma_{k}$ in (9).

In this paper we shall use for the following a theorem that is not hard to prove [1].

Theorem - 1. Let $x_{0} \in H_{1}, \quad S=\left\{x \in H_{1}:\left\|x-x_{0}\right\| \leqslant 0\right\}$ and let $P_{R(x)} F(x)$ be a continuous operator fulfilling condition $(\mathrm{A})$ and the inequality

$$
\left\|Q\left(x_{k}, A_{k}\right)\right\| \leqslant \lambda\left\|P_{k} F\left(x_{k}\right)\right\| \quad(0<\lambda<\infty)
$$

be valid in $S$.

Then 1) If $p=1$ or $\gamma_{k} \leqslant \gamma \neq 0, r_{1}=\lambda\left\|P_{0} F\left(x_{0}\right)\right\| /(1-\delta) \leqslant \varrho, \delta=\delta_{0}^{(1)}<1$ then the equation $\left[F^{\prime}(x)\right]^{*} F(x)=0$ has a solution $x^{*}$ in $S$, to which the sequence (2) converges with $\left\|x^{*}-x_{0}\right\| \leqslant r_{1}$ and

$$
\left\|x_{k}-x^{*}\right\| \leqslant r_{1} \delta^{k}
$$

if $p \geqslant 2$ provided $\gamma_{0} \geqslant \gamma_{1} \geqslant \ldots \geqslant \gamma_{k} \geqslant \ldots \geqslant 0$, then $\delta_{k}^{(1)} \searrow 0$ and the sequence (2) converges superlinearly, i.e.,

$$
\left\|x_{k}-x^{*}\right\| \leqslant r_{1} \prod_{i=0}^{k-1} \delta_{i}^{(1)}
$$

2) if $p \geqslant 2$ and quantities $\gamma_{k}(k=0,1, \ldots)$ are expressed in the form (B) 
or $\gamma_{k}=0,(k=0,1, \ldots), \delta=\sqrt[p-1]{\sqrt{d_{0} b_{0}}}<1, r_{p} \leqslant\left.\lambda H_{0}(\delta)\right|^{p-1} \sqrt{d} \leqslant \mathrm{Q}$ where $d=$ $=\lim _{k \rightarrow \infty} d_{k}$ and

$$
H_{k}(\delta)=\sum_{i=k}^{\infty} \delta^{p^{t}},
$$

then the equation $\left[F^{\prime}(x)\right]^{*} F(x)=0$ has a solution $x^{*}$ in $S$, to which the sequence (2) converges, with $\left\|x^{*}-x_{0}\right\| \leqslant r_{p}$ and

$$
\left\|x_{k}-x^{*}\right\| \leqslant\left(\left.\lambda\right|^{p-1} \sqrt{d}\right) H_{k}(\delta) .
$$

From this theorem, in a special case, $A_{k}=\left[F^{\prime}\left(x_{k}\right)\right]^{+}$, the convergence for the analogues of the generalizations of the well-known rapidly convergent iterative methods, such as Newton's, Chebyshev's methods, etc., to a solution of the equation (1) concludes, and estimations for the rate of convergence follow $[1,2]$.

Corollary. Let $\tau$ be a real number, $2 \leqslant \tau<p-1$. If a) $q \geqslant \tau$ and $a_{v}+b_{v} \geqslant \tau$ with $\omega_{v} \neq 0$ or b) $q \geqslant \frac{\tau(\tau-s)}{l}$ and $l<\tau-s$, then the order of the convergence for iterative procedure (2) is equal to $\tau$.

2. We shall now state two facts which will be useful in the sequel.

Remark 1. Suppose that $F^{\prime}(x)$ and $\left[F^{\prime}(x)\right]^{+}$satisfy Lipschitz condition in a certain region $S$ :

$$
\begin{gathered}
\left\|F^{\prime}(x)-F^{\prime}(y)\right\| \leqslant L_{1}\|x-y\| \quad(x, y \in S), \\
\left\|\left[F^{\prime}(u)\right]^{+}-\left[F^{\prime}(v)\right]^{+}\right\| \leqslant L\|u-v\| \quad(u, v \in S),
\end{gathered}
$$

then

$$
\begin{gathered}
\left\|P_{R(x)}-P_{R(y)}\right\| \leqslant L_{0}\|x-y\|, \\
\left\|\left(P_{k+1}-P_{k+1} P_{k}\right) F\left(x_{k}\right)\right\| \leqslant G\left\|P_{k} F\left(x_{k}\right)\right\|^{2},
\end{gathered}
$$

where $G=\lambda L_{0}\left(1+\lambda L_{0} F\right)$ and $F=\sup _{x \in S}\|F(x)\|$.

Remark 2. If $F(x)$ is Lipschitz continuous and

$$
\left\|\left(P_{R(y)}-P_{R(y)} P_{R(x)}\right) F(x)\right\| \leqslant N_{0}\|x-y\|,
$$

then $P_{R(x)} F(x)$ is continuous [1].

If (10) and (11) are valid, then the continuity of $P_{R(x)} F(x)$ follows from (12).

For solving (1) we now make use of the following iterative method:

$$
\begin{aligned}
& x_{k+1}=x_{k}-D_{k}\left[F^{\prime}\left(x_{k}\right)\right]^{*} F\left(x_{k}\right), \\
& D_{k+1}=2 D_{k}-D_{k}\left[F^{\prime}\left(x_{k+1}\right)\right]^{*} F^{\prime}\left(x_{k+1}\right) D_{k}
\end{aligned}
$$

where the starting operator $D_{0}$ is close enough to $\left\{\left[F^{\prime}\left(x_{0}\right)\right]^{*} F^{\prime}\left(x_{0}\right)\right\}^{+}$with $D_{0}=P_{0}^{*} D_{0}=D_{0} P_{0}^{*}\left[{ }^{7}\right]$.

Since $F^{\prime}(x)$ has a closed range, then it has the bounded pseudoinverse $\left[F^{\prime}(x)\right]^{+}\left[{ }^{8}\right]$. Let $\beta_{k}(k=0,1, \ldots) C$ and $N$ be quantities satisfying the inequalities

$$
\left\|P_{k+1}-F^{\prime}\left(x_{k+1}\right) A_{k}\right\| \leqslant \beta_{k}, \quad\left\|\left[F^{\prime}(x)\right]+\right\| \leqslant C, \quad x \in S,
$$




$$
\left\|P_{R(y)}-P_{R(y)} P_{R(x)}\right\| \leqslant N, \quad\left\|P_{R^{*}(y)}-P_{R^{*}(y)} P_{R^{*}(x)}\right\| \leqslant N, \quad(x, y \in S) .
$$

Denote by

$\gamma_{0}=\max \left\{\left(\beta_{0}+h_{1}\left\|P_{0} F\left(x_{0}\right)\right\|\right)^{2},\left\|P_{0}-F^{\prime}\left(x_{0}\right) A_{0}\right\|\right\}, \quad b_{k}=\max \left\{\gamma_{k},\left\|P_{k} F\left(x_{k}\right)\right\|\right\}$.

Expressions for $\gamma_{k}$ and $\beta_{k}$ will be given below.

Putting

$$
A_{k}=D_{k}\left[F^{\prime}\left(x_{k}\right)\right]^{*}, \quad B_{k}=\left[F^{\prime}\left(x_{k}\right)\right]^{*} F^{\prime}\left(x_{k}\right)
$$

as a corollary of Theorem 1 it follows

Theorem 2. Let $x_{0} \in H_{1}, S=\left\{x \in H_{1}:\left\|x-x_{0}\right\| \leqslant 0\right\}$ and let in $S$ be valid the following conditions:

$1^{\circ}$ operator $F(x)$ has Fréchet-derivative $F^{\prime}(x)$;

$2^{\circ}$ derivative $F^{\prime}(x)$ satisfies Lipschitz condition, i.e.,

$$
\left\|F^{\prime}(x)-F^{\prime}(y)\right\| \leqslant L_{1}\|x-y\| \text { for all } x, y \in S .
$$

1) If the operators $F^{\prime}(x)$ and $F^{\prime}(y)$ are in the acute case* and for any $x, y \in S\left\|\left(P_{R(y)}-P_{R(y)} P_{R(x)}\right) F(x)\right\| \leqslant N_{0}\|x-y\|, \beta_{1}=\gamma_{0}+N+L_{1} \lambda^{2}\left\|P_{0} F\left(x_{0}\right)\right\| \leqslant$

$\leqslant \beta_{0}, \quad \delta=\delta_{0}^{(1)}=\gamma_{0}+N_{0} \lambda+\frac{1}{2} L_{1} \lambda^{2}\left\|P_{0} F\left(x_{0}\right)\right\|<1, \quad r_{1}=\lambda\left\|P_{0} F\left(x_{0}\right)\right\| /(1-\delta) \leqslant \mathrm{Q}$,

then the equation $\left[F^{\prime}(x)\right]^{*} F(x)=0$ has in $S$ a solution $x^{*}$, to which the sequence $(15)-(16)$ converges with $\left\|x^{*}-x_{0}\right\| \leqslant r_{1}$ and

$$
\left\|x_{k}-x^{*}\right\| \leqslant r_{1} \delta^{k}
$$

2) If $\left\|\left[F^{\prime}(x)\right]^{+}-\left[F^{\prime}(y)\right]^{+}\right\| \leqslant L\|x-y\|, \beta_{1}=\gamma_{0}+h_{1}\left\|P_{0} F\left(x_{0}\right)\right\| \leqslant \beta_{0}, L_{0} r_{2}<1$, $\delta=\delta^{(2)}=d b_{0}<1, \quad r_{2}=\lambda H_{0}(\delta) / d$, where $h_{1}=L_{0} \lambda f L_{1} \lambda^{2}$ and $H_{k}(\delta)=\sum_{i=k}^{\infty} \delta^{2 t}$, then the sequence (15) - (16) converges quadratically with $\left\|x^{*}-x_{0}\right\| \leqslant r_{2}$ and

$$
\left\|x_{k}-x^{*}\right\| \leqslant r_{2} H_{k}(\delta) / d,
$$

where $d=\max \left\{\left(1+h_{0}+h_{1}\right)^{2}, 1+h_{2}\right\}, h_{0}=C\left(1+\beta_{0}\right) \lambda L_{1} /\left(1-L_{2} r_{2}\right), h_{2}=$ $=G+\frac{1}{2} L_{1} \lambda^{2}$. If, in addition, to Lipschitz continuity of $\left[F^{\prime}(x)\right]^{+}$the inequalities $R\left(x_{k}\right) \supseteq R\left(x_{k+1}\right)$ are fullfilled, then $h_{1}=L_{1} \lambda^{2}$ and $h_{2}=\frac{1}{2} L_{1} \lambda^{2}$.

P r o of. Let $T$ be a linear bounded operator from $H_{1}$ into $H_{2}$ with the closed range $R(T)$.

It is well-known that

$$
\begin{gathered}
T^{*+}=T^{+*}, \quad P_{R(T)}=T T^{+}=T^{+*} T^{*}, \quad T^{+}=T+P_{R(T)}, \quad T^{*}=T^{*} P_{R(T)}, \\
P_{R\left(T^{*}\right)} T^{*}=T^{*}, \quad P_{R\left(T^{*}\right)}=T+T .
\end{gathered}
$$

From (16) and (20) it is evident that $P_{0}{ }^{*} A_{k}=A_{k}$ provided $D_{0}=P_{0}{ }^{*} D_{0}$. Apparently, then $P_{k}{ }^{*} A_{k}=P_{k}{ }^{*} P_{0}{ }^{*} A_{k}$ and by $(3),(20)-(21)$ we have $\left\|Q\left(x_{k}, A_{k}\right)\right\|=\left\|A_{k}\right\|=\left\|\left[F^{\prime}\left(x_{k}\right)\right]^{+}\left[P_{k}+F^{\prime}\left(x_{k}\right) A_{k}-P_{k}+\left(P_{0}^{*}-P_{0}^{*} P_{k}^{*}\right) A_{k}\right]\right\|$.

Moreover by (16), (17), (20)

* Definition. The linear operators $A$ and $B$ are said to be in the acute case if $R(A)$ and $R(B)$ are in the acute case as well as $R\left(A^{*}\right)$ and $R\left(B^{*}\right)\left[{ }^{9}\right]$. 


$$
\begin{gathered}
\left\|F^{\prime}\left(x_{k}\right) D_{k-1} P_{k-1}^{*}\right\|=\left\|F^{\prime}\left(x_{k}\right) A_{k-1}\left[F^{\prime}\left(x_{k-1}\right)\right]^{*+}\right\| \leqslant C\left(1+\beta_{k-1}\right), \\
\left\|F^{\prime}\left(x_{k}\right) D_{k-1}\right\| \stackrel{\dot{=}}{=}\left\|F^{\prime}\left(x_{k}\right) D_{k-1} P_{0}^{*}\right\|=\| F^{\prime}\left(x_{k}\right) D_{k-1} P_{k-1}^{*}+ \\
+F^{\prime}\left(x_{k}\right) D_{k-1}\left(P_{0}^{*}-P_{0}^{*} P_{k-1}^{*}\right) \| .
\end{gathered}
$$

On the basis of Taylor expression

$$
\begin{gathered}
P_{k+1} F\left(x_{k+1}\right)=\left(P_{k+1}-P_{k+1} P_{k}\right) F\left(x_{k}\right)+P_{k+1}\left\{\left(P_{k}-F^{\prime}\left(x_{k}\right) A_{k}\right) F\left(x_{k}\right)+\right. \\
\left.+\int_{0}^{1}\left[F^{\prime}\left(x_{k}\right)-F^{\prime}\left(x_{k}+t\left(x_{k+1}-x_{k}\right)\right)\right] A_{k} F\left(x_{k}\right) d t\right\} .
\end{gathered}
$$

Using (16)-(21), we obtain

$$
\begin{gathered}
\left\|P_{k}-F^{\prime}\left(x_{k}\right) A_{k}\right\|=\left\|P_{k}-F^{\prime}\left(x_{k}\right) D_{k}\left[F^{\prime}\left(x_{k}\right)\right]^{*}\right\| \leqslant \\
\leqslant\left\|\left(P_{k}-F^{\prime}\left(x_{k}\right) D_{k-1}\left[F^{\prime}\left(x_{k}\right)\right]^{*}\right)\right\|^{2}, \\
\left\|P_{k}-F^{\prime}\left(x_{k}\right) D_{k-1}\left[F^{\prime}\left(x_{k}\right)\right]^{*}\right\| \leqslant\left\|P_{k}-F^{\prime}\left(x_{k}\right) A_{k-1}\right\|+ \\
+\left\|F^{\prime}\left(x_{k}\right) D_{k-1}\left(\left[F^{\prime}\left(x_{k-1}\right)\right]^{*}-\left[F^{\prime}\left(x_{k}\right)\right]^{*}\right)\right\| .
\end{gathered}
$$

It is plain that we may write

$$
\begin{gathered}
\left\|P_{k}-F^{\prime}\left(x_{k}\right) A_{k-1}\right\| \leqslant\left\|P_{k}\left(P_{k-1}-F^{\prime}\left(x_{k-1}\right) A_{k-1}\right)\right\|+\left\|\left(P_{k}-P_{k} P_{k-1}\right)\right\|+ \\
+\left\|F^{\prime}\left(x_{k}\right)-F^{\prime}\left(x_{k-1}\right)\right\|\left\|A_{k} F\left(x_{k}\right)\right\| .
\end{gathered}
$$

1) If $F^{\prime}(x)$ and $F^{\prime}(y)$ are in the acute case, then $N<1\left[{ }^{9}\right]$ and this with (22), (23), (27) and $\delta<1$ implies that

$$
\begin{gathered}
\left\|A_{k}\right\| \leqslant C\left(1+\gamma_{k}\right) /(1-N), \quad\left\|F^{\prime}\left(x_{k}\right) D_{k-1}\right\| \leqslant C\left(1+\beta_{k-1}\right) /(1-N), \\
\left\|P_{k}-F^{\prime}\left(x_{k}\right) A_{k-1}\right\| \leqslant \gamma_{k-1} f N+\lambda^{2} L_{1}\left\|P_{k-1} F\left(x_{k-1}\right)\right\| .
\end{gathered}
$$

Therefore it is sufficient to take for $\lambda=\sup \left\{\lambda_{k}\right\}$ with $\lambda_{k}=C\left(1+\gamma_{k}\right) /(1-N)$ and

$$
\beta_{k-1}=\gamma_{k-1}+N+\lambda^{2} L_{1}\left\|P_{k-1} F\left(x_{k-1}\right)\right\| .
$$

Because of $(25),(26)$ and $\beta_{k} \leqslant \beta_{0}$ we get

$$
\left\|P_{k}-F^{\prime}\left(x_{k}\right) D_{k-1}\left[F^{\prime}\left(x_{k}\right)\right]^{*}\right\| \leqslant \beta_{k-1}+h_{0}\left\|P_{k-1} F\left(x_{k-1}\right)\right\|,
$$

where $h_{0}=C\left(1+\beta_{0}\right) \lambda L_{1} /(1-N)$, and we can determine $\gamma_{k}$ by $\gamma_{k}=$ $=\left(\beta_{k-1}+h_{0}\left\|P_{k-1} F\left(x_{k-1}\right)\right\|\right)^{2}$. From (24) we see that

$$
\left\|P_{k+1} F\left(x_{k+1}\right)\right\| \leqslant\left(\gamma_{k}+N_{0} \lambda+\frac{1}{2} L_{1} \lambda^{2}\left\|P_{k} F\left(x_{k}\right)\right\|\right)\left\|P_{k} F\left(x_{k}\right)\right\|=\delta_{k}\left\|P_{k} F\left(x_{k}\right)\right\| .
$$

Since $\delta_{0}<1, \beta_{1} \leqslant \beta_{0}$ we obtain by induction that $\beta_{k} \leqslant \beta_{0}, \gamma_{k} \leqslant \gamma_{0}, \lambda_{k} \leqslant \lambda_{0}=$ $=C\left(1+\gamma_{0}\right) /(1-N)=\lambda$ and $\delta_{k} \leqslant \delta_{0}<1$.

2) Now taking into account Remark 1, we have

$$
\begin{gathered}
\left\|P_{h}-P_{k} P_{k-1}\right\| \leqslant\left\|P_{k}-P_{k-1}\right\| \leqslant L_{0} \lambda\left\|P_{k-1} F\left(x_{k-1}\right)\right\|, \\
\left\|P_{0}-P_{k}\right\| \leqslant L_{0}\left\|x_{0}-x_{k}\right\| \leqslant L_{0} r_{2},
\end{gathered}
$$

so that

$$
\beta_{k-1}=\gamma_{k-1}+h_{1}\left\|P_{k-1} F\left(x_{k-1}\right)\right\|, \quad \lambda=C\left(1+\gamma_{0}\right) /\left(1-L_{0} r_{2}\right),
$$

$\left\|P_{k+1} F\left(x_{k+1}\right)\right\| \leqslant \gamma_{k}\left\|P_{h} F\left(x_{k}\right)\right\|+\left(G+\frac{1}{2} L_{1} \lambda^{2}\right)\left\|P_{k} F\left(x_{k}\right)\right\| \leqslant\left(1+h_{2}\right) b_{k}^{2}$, 
where $h_{1}=L_{0} \lambda+L_{1} \lambda^{2}$ and $h_{2}=G+\frac{1}{2} L_{1} \lambda^{2}$.

Since

$$
\|\left(P_{k}-F^{\prime}\left(x_{k}\right) \cdot A_{k} \| \leqslant\left(\beta_{k-1}+h_{0}\left\|P_{k-1} F\left(x_{k-1}\right)\right\|\right)^{2}\right.
$$

with $h_{0}=C\left(1+\beta_{0}\right) \lambda L_{1} /\left(1-L_{0} r_{2}\right)$, we can define $\gamma_{k}$ by

$$
\gamma_{k}=\left(\gamma_{k-1}+h\left\|P_{k-1} F\left(x_{k-1}\right)\right\|\right)^{2}, \quad h=h_{1}+h_{0} .
$$

From (24) and (27) it is evident that $s=l=1$ and $p=2$.

With a consideration of all these results, a straightforward application of Theorem 1 yields Theorem 2 .

Consider

$$
\begin{gathered}
x_{k+1}=x_{k}-A_{k} F\left(x_{k}\right), \\
D_{k+1}=D_{k}+\alpha_{k+1}\left(I_{1}-B_{k+1} D_{k}\right),
\end{gathered}
$$

where $A_{k}$ and $B_{k+1}$ are as in (20), $I_{1}$ - identity operator in $H_{1}, \alpha_{k+1}$ is a real number, $0<\alpha_{k+1}<2 / M^{2},\left\|F^{\prime}(x)\right\| \leqslant M$.

Denote

$$
\gamma_{0}=\max \left\{\mu \beta_{0}+\mu h_{1}\left\|P_{0} F\left(x_{0}\right)\right\|, \quad\left\|P_{0}-F^{\prime}\left(x_{0}\right) A_{0}\right\|\right\},
$$

where $\mu=\sup _{k}\left\{\mu_{k}\right\}, \quad\left\|P_{k}-\alpha_{k} F^{\prime}\left(x_{k}\right)\left[F^{\prime}\left(x_{k}\right)\right]^{*}\right\| \leqslant \mu_{k}$.

Theorem 3. Let $x_{0} \in H_{1}, S=\left\{x \in H_{1}:\left\|x-x_{0}\right\| \leqslant \mathrm{e}\right\}$, and let in $S$ the conditions $1^{\circ}-2^{\circ}$ of Theorem 2 be valid.

If $\left\|\left[F^{\prime}(x)\right]^{+}-\left[F^{\prime}(y)\right]^{+}\right\| \leqslant L\|x-y\|, \quad R^{*}\left(x_{0}\right) \supseteq R^{*}(x), \quad \beta_{1}=\gamma_{0}+$ $+h_{1}\left\|P_{0} F\left(x_{0}\right)\right\| \leqslant \beta_{0}, \quad \delta=\gamma_{0}+h_{2}\left\|P_{0} F\left(x_{0}\right)\right\|<1, \quad L_{0} r<1, \quad r=\lambda\left\|P_{0} F\left(x_{0}\right)\right\| /$ $/(1-\delta) \leqslant 0$, then the equation $\left[F^{\prime}(x)\right]^{*} F(x)=0$ has, in $S$, a solution $x^{*}$, to which the sequence (29)-(30) converges superlinearly with $\left\|x^{*}-x_{0}\right\| \leqslant r_{1}$, and

$$
\left\|x_{k}-x^{*}\right\| \leqslant r_{1} \prod_{i=0}^{k-1} \delta_{i},
$$

where $\delta_{i}=\gamma_{i}+h_{2}\left\|P_{i} F\left(x_{i}\right)\right\|$, and $h_{i}(i=1,2)$ are as in Theorem 2.

Proof. From (29)-(31) it follows easily that

$$
\begin{gathered}
\left\|P_{k}-F^{\prime}\left(x_{k}\right) A_{k}\right\|=\|\left(P_{k}-\alpha_{k} F^{\prime}\left(x_{k}\right)\left[F^{\prime}\left(x_{k}\right)\right]^{*}\right) \times \\
\times\left(P_{k}-F^{\prime}\left(x_{k}\right) D_{k-1}\left(\left[F^{\prime}\left(x_{k-1}\right)\right]^{*}+\left[F^{\prime}\left(x_{k}\right)\right]^{*}-\left[F^{\prime}\left(x_{k-1}\right)\right]^{*}\right) \| \leqslant\right. \\
\leqslant \mu\left(\beta_{k-1}+h_{0}\left\|P_{k-1} F\left(x_{k-1}\right)\right\|\right) .
\end{gathered}
$$

The condition $R^{*}\left(x_{0}\right) \supseteq R^{*}(x)$ is only needed for bounding $\left\|A_{k}\right\|$, because then $P_{0}{ }^{*} D_{k}=D_{k}$.

The rest of it is analogous to proof of Theorem 2 .

3 . Note that for choosing $\left\{A_{k}\right\}$ we can employ iterative procedures of the higher order $q \geqslant 2$, and for defining $Q\left(x, A_{k}\right)$ we can make use of a formula generating iterative process of the order $p \geqslant 2$ following $\left[{ }^{1-5}\right]$. Because of their susceptibility to errors, the convergence rate of iterative methods of a higher order is probably too slow to be of practical value in the actual solution, considering the labour involved in obtaining the iterates.

As applied to the solution of nonlinear systems of an algebraic system, the methods (15)-(16) and (29) - (30) require only slightly higher computational efforts than those of $\left[{ }^{10}\right]$. However, we proved 
the convergence of methods $(15)-(16)$ and $(29)-(30)$ to a solution of the equation (1) under weaker assumptions and achieved better bounds on the rate of convergence than by methods of [ $\left.{ }^{1}\right]$.

Finally, note that it is difficult to say which is the best criterion for comparing certain computational techniques, and that is why in this paper no claim is made for judging the efficiency of methods.

As an illustration of the above methods, we consider some computational experiments. The methods were tested on the following problems taken from the literature [ $\left.{ }^{11}\right]$.

$\mathrm{Ex}$ a m p le 1. The system of equations is

$$
F(x)=\left\{\begin{array}{l}
f_{1}=x_{1}^{2}+x_{2}^{2}-2=0, \\
f_{2}=x_{1}-x_{2}=0 \\
f_{3}=x_{1} x_{2}-1=0,
\end{array}\right.
$$

whose solutions are $(1,1)$ and $(-1,-1)$.

Example 2 .

$$
F(x)=\left\{\begin{array}{l}
f_{1}=x_{1}^{2}+x_{2}^{2}-2=0, \\
f_{2}=\left(x_{1}-2\right)^{2}+x_{2}^{2}-2=0, \\
f_{3}=\left(x_{1}-1\right)^{2}+x_{2}^{2}-9=0,
\end{array}\right.
$$

whose least squares solutions are $(1.00000 ; \pm 1.914854)$ and $\min _{i}^{3} f_{i}^{2}=42.666667$.

For solving this equations, we apply the following algorithms

$$
\begin{array}{rlrl}
1^{\circ} x_{k+1} & =x_{k}-\left[F^{\prime}\left(x_{k}\right)\right]^{+} F\left(x_{k}\right), & 5^{\circ} x_{k+1}=x_{k}-D_{k}\left[F^{\prime}\left(x_{k}\right)\right]^{*} F\left(x_{k}\right), \\
2^{\circ} x_{k+1} & =x_{k}-\left[F^{\prime}\left(x_{0}\right)\right]^{+} F\left(x_{k}\right), & & D_{k+1}=2 D_{k}-D_{k} B_{k+1} D_{k}, \\
3^{\circ} x_{k+1} & =x_{k}-D_{k}\left[F^{\prime}\left(x_{k}\right)\right]^{*} F\left(x_{k}\right), & & 6^{\circ} x_{k+1}=x_{k}-\left[2 D_{k}-D_{k} B_{k} D_{k}\right]\left[F^{\prime}\left(x_{k}\right)\right]^{*} F\left(x_{k}\right), \\
D_{k+1} & =D_{k}+\alpha_{k+1}\left(I_{1}-B_{k+1} D_{k}\right), & D_{k+1}=2 D_{k}-D_{k} B_{k+1} D_{k}, \\
4^{\circ} x_{k+1} & =x_{k}-\left[2 D_{k}-D_{h} B_{k} D_{k}\right]\left[F^{\prime}\left(x_{k}\right)\right]^{*} F\left(x_{k}\right), \\
D_{k+1} & =D_{k}+\alpha_{k+1}\left(I_{1}-B_{k+1} D_{k}\right), & &
\end{array}
$$

\begin{tabular}{|c|c|c|c|c|c|c|c|c|c|c|c|}
\hline Example & $\begin{array}{l}\text { Initial } \\
\text { guess }\end{array}$ & $1^{\circ}$ & $2^{\circ}$ & $3^{\circ} a$ & $3^{\circ} \mathrm{b}$ & $4^{\circ} a$ & $4^{\circ} \mathrm{b}$ & $5^{\circ} a$ & $5^{\circ} b$ & $6^{\circ} a$ & $6^{\circ} b$ \\
\hline 1 & $\begin{array}{l}3 \\
2\end{array}$ & 6 & 26 & 9 & 11 & 7 & 9 & 8 & 10 & 7 & 9 \\
\hline 2 & $\begin{array}{l}10 \\
20\end{array}$ & 8 & 95 & 28 & 13 & $(-)$ & 12 & $(-)$ & 15 & $(-)$ & 14 \\
\hline 2 & $2^{1,5}$ & 5 & 7 & 8 & 10 & 6 & 8 & 7 & 8 & 6 & 6 \\
\hline
\end{tabular}

where $\quad \alpha_{k}=\frac{3}{2 M_{k}}, \quad M_{k}=\max _{i} \Sigma\left|b_{i j}^{(k)}\right|, \quad\left[F^{\prime}\left(x_{k}\right)\right]^{*} F^{\prime}\left(x_{k}\right)=\left(b_{i j}^{(k)}\right)$.

The algorithms were considered to have converged to the desired solution when the inequality $\left\|x_{k+1}-x_{k}\right\| \leqslant \varepsilon=0.0000010$ was satisfied. In the tab'e we give the number of iterations required to obtain convergence.

The figures $a$ and $b$ denote that the process was started with $D_{0}=B_{0}^{+}$and $D_{0}=\alpha_{0} I_{1}$ respectively, but $(-)$ fails to converge.

\section{REFERENCES}

1. В а а р м н н О. О сходимости методов с последовательной аппроксимацией псевдообратного оператора. № 3094-76 Деп. Новосибирск, 1976.

2. В а а рм ан О. О сходимости итерационных методов с использованием псевдо- 
обратного оператора или его аппроксимации. - В кн.: Тезисы II Всесоюз. семинара, 31 мая - 3 июня 1976, Харьков. Харьков, 1976, с. 95-99.

3. Лика Д. К., Шафиев Р. А. Об усиленном методе Ньютона-Канторовича с последовательной аппроксимацией в гильбертовом пространстве. - В кн.: Приближенное решение уравнений. Кишинев, 1973, с. $24-29$.

4. Ш афие в Р. А. Об аппроксимашионном аналоге усиленного метода НьютонаКанторовича. - Изв. АН МолдССР, Сер. физ.-техн, и матем., 1975, № 3, c. $16-23$.

5. $\mathrm{V}$ a a rmann, O. On methods with succesive approximation of the pseudoinverse operator. - In: Colloquia Mathematica Societatis János Bolyai (12. Progress in Operations Research). Eger (Hungary), 1974, p. 941-946.

6. В а а р манн О. Об ускорении методов с последовательной аппроксимащией псевдообратного оператора. - Изв. АН ЭССР, Физ. Матем., 1975, т. 24, № 2. c. $239-242$.

7. Showalter, D. W., Ben-Israel, A. Representation and computation of the generalized inverse of a bounded linear operator between two Hilbert spaces. Atti Accad. Naz. Lincei. Mem., Ser. 8, 1970, v. 48, p. 184--194.

8. Desoer, C. A., Whale n, B. H. A note on pseudoinverses. - SIAM J. Appl. Math., 1963, v. 11, N 2, p. 442-447.

9. We din, P.-A. Perturbation theory for pseudoinverses. - BIT, 1973, v. 13, p. 217232.

10. В а а р м а н н О. О применении обобщенных обратных операторов и их приближений для решения нелинейных уравнений. - Изв. АН ЭССР, Физ. Матем., 1970, т. 19 , № 3, c. $265-274$.

11. Ben-Israel, A. A Newton-Raphson method for the solution of systems of equations. - J. Math. Anal. Appl., 1966, v. 15, N 2, p. 243-253.

Academy of Sciences of the Estonian SSR,

Institute of Cybernetics

Received

Apr. 25, 1977

O. VAARMANN

\section{MŌNED ITERATSIOONIMEETODID MITTELINEAARSE VÄHIMRUUTUDE OLESANDE LAHENDAMISEKS}

Mittelineaarse vähimruutude ülesande lahendamiseks Hilberti ruumis on konstrueeritud kaks iteratsioonimeetodit (koonduvusjärk p >1), mis põhinevad pseudopöördoperaatori järkjärgulisel aproksimeerimisel. On tõestatud valemitega (15)-(16) ja (29)-(30) defineeritud iteratsiooniprotsesside koonduvus vōrrandi (1) lahendiks ning antud koondumiskiiruse hinnangud. Teoreetiliste väidete illustreerimiseks on lahendatud kaks näiteülesannet, mis käsitlevad mittelineaarsete võrrandisüsteemide lahendi määramist vähimruutude mõttes.

\section{O. BAAPMAHH}

\section{НЕКОТОРЫЕ ИТЕРАЦИОННЫЕ МЕТОДЫ ДЛЯ РЕШЕНИЯ НЕЛИНЕИНОЯ ЗАДАЧИ НАИМЕНЬШИХ КВАДРАТОВ}

Для решения нелинейной задачн наименьших квадратов построены два быстросходящихся итеращионных метода с последовательной аппроксимацией псевдообратного оператора. Доказана сходимость итерационных процессов (15)-(16) и (29)-(30) к решению уравнения (1) и установлены оценки для их скорости сходимости. Теоретические соображения иллюстрированы числовыми примерами. 